\title{
Nowcasting of Economic Development Indicators Using the NBU's Business Survey Results
}

\author{
Roman Lysenko \\ National Bank of Ukraine
}

\author{
Nataliia Kolesnichenko \\ National Bank of Ukraine
}

\section{ABSTRACT}

The article explores the possibilities to use Business Outlook Survey results, which are carried out by the National Bank of Ukraine, for the short-term forecasting of economic development indicators, in particular, the Gross Domestic Product of Ukraine. The different methods of building of the leading index of economic development, their advantages, and their restrictions are examined. The choice of the best index, which provides for the higher accuracy of forecasting the GDP, is carried out with the use of econometric models.

\section{JEL Codes: E3, E4, E5}

Keywords: business expectations, business outlook survey, GDP, nowcasting

\section{INTRODUCTION}

The generally acknowledged world practice is the use of survey results of economic agents (including enterprises) concerning the future expectations of economic development for the forecasting of the main macroeconomic variables, such as economic activities, consumption, investments, industrial production, employment, etc.

Usually the expectations are qualitative, that is, non-quantitative data, which characterize the personal assessment by enterprises of their current and forecasted business activity. The questions may concern a wide range of information regarding enterprises activities, flexibly adapt to the analytical needs of the survey's customers, and include information that official statistics do not contain. The main advantage of surveys is that their results usually precede the publication of actual statistical data, which creates the possibility to make a preliminary assessment, for example, of such an indicator as the Gross Domestic Product (hereinafter referred to as GDP).

For this purpose, the surveys are based on leading indicators of economic development in general and under different directions - consumption, investments, demand, employment, etc. - for short-term assessments of economic development, in particular, for assessing turning points of economic cycle. The forecasting horizon may range from one quarter up to one year and depends on the questions' horizon (for the next quarter or year). The expectations under separate questions or indicators are aggregated as the balance of answers - the difference between the share of the respondents' answers who expect the indicator to improve or grow, and the share of the respondents' answers who expect the indicator to worsen or decrease. The aggregate index is the business expectation index and is based on the balances of expectations under several questions.

The most widespread are the following methods of index building:

- With the help of definition of the medium or the average weighted value of the respondents' balance of answers;

- With the help of the principle components method;

- With the help of the factor analysis. 
The key problem of building the business expectation index is defining the list of indicators that shall be taken into account during its composition, and the choice of the most adequate methods of index composition. A large number of indicators complicates the possibilities for index building, and the artificial restriction increases the risk of non-accounting of the essential factors, which influence the dynamics of macroeconomic indicators.

The index example, which is calculated using the medium or the average weighted value of the surveys subjects' assessments, may be the Purchasing Managers' Index, which is used in the Manufacturing ISM Report on Business (more commonly known as PMI ISM in the services sector, production sector, and business activities of the companies registered in New York). This is a composite index of three seasonally adjusted indicators with equal weights. Notwithstanding the sufficiently simple calculation methods, PMI ISM is a quite powerful indicator, which provides the possibility to assess the dynamics of economic development over a short-term period. The obvious advantage of this method is its simplicity; however, a significant risk of influence by subjective factors exists (weight values).

In its turn, the principle components method is also quite widespread and is used for the calculation of the Ifo Business Climate Index (Germany), the Purchasing Managers' Index (the EU), the Synthetic Economic Barometer (Bank of Belgium), and Business Confidence (Reserve Bank of Australia), i.e., in countries where there are no shock transformations and the sharp changes in the economic activities conditions. According to Pichette (2012), the use of the principle components method provides the possibility to avoid subjectivity while choosing indicators, which are included into the index, and that is particularly important during calculation of the weights of the indicators, which are included into the index's composition.

The National Bank of Ukraine (hereinafter referred to as the NBU) has carried out quarterly Business Outlook Survey since 2006. Similar to other institutions that carry out surveys, the NBU calculates the aggregate index of the survey's results - the Business Expectation Index (hereinafter referred to as the BEI), which is based on the enterprises expectations concerning the prospects of their development in the next 12 months, in particular, concerning the financial and economic conditions, volumes of products and services sales, investments, and employment. The BEI is calculated as the average value of the balances of answers. Based on the principles of index building, it must be a leading indicator of economic development with a one year interval, that is, to have the possibility to help in forecasting of GDP. Meanwhile, previous researches (Kolesnichenko, 2010; Petryk \& Kolesnichenko, 2012) certify that the BEI reflects mainly the current economic development. In particular, their calculations indicate on the presence of a significant direct relationship between the BEI and the GDP in the current quarter, and with an increase in the time lag, the relationship deteriorates. Therefore, the current methods of BEI calculation give contradictory results. However, even in such conditions the BEI can be used as the leading indicator of Ukrainian economic development, at least with a lag of one quarter in advance, because the previous assessment of the GDP is published by State Statistics Service of Ukraine (hereinafter referred to as the SSSU) 45 days after the end of the reported quarter, and their expanded assessment after 90 days. Meanwhile, the BEI gives the possibility to carry out the assessment of the GDP already at the end of the current quarter.

The use of the principle components method for building an alternative leading indicator based on the Business Outlook Survey results, theoretically can improve the quality and increase the forecasting horizon of the GDP. This requires analysis of the interconnection between the index's dynamics and the dynamics of real GDP and a comparison with the relationship between the GDP and the BEI. An important step will become the building and assessment of econometric models for the forecasting of GDP and its components with the use of the BEI and the index, built under the principle components method. This will allow for the possibility of reasoned choice the best model for nowcasting of GDP.

This paper is organized as follows: Section II contains a review of the literature devoted to the building of leading indicators under the Business Outlook Survey results and the assessment of the interconnection between such indicators and the actual indicators of economic development, in particular, GDP. Section III outlines the main characteristics of the Business Outlook Surveys, which are carried out by the NBU and cover aggregate index building by the principle components method and analysis of this index. Section IV contains a comparative assessment of the interconnection between the GDP, the BEI and the index built under the principle components method. In the same section are models built for the forecasting of GDP and its components with the use of these indicators, as well as their assessment, which was made based on a reasoned choice of the best index for forecasting GDP over the short-term period. In the last section, the conclusions under the study results are given.

\section{LITERATURE REVIEW}

In studies, where issues of use of Business Outlook Survey are examined for the assessment and forecasting of economic activities indicators (in particular, the dynamics of GDP), as a rule, three main tasks are resolved:

1. Do we need to include the survey results as an additional index into the composition of a complex macroeconomic model or build the model on the basis of only the business expectation index and assess its influence on the macroeconomic variables (for example, GDP)? 
2. Is it appropriate to build an aggregate business expectation index? Will it really have a higher forecasting capability than the enterprises' answers to separate questions, for example, concerning investments, sales volumes, etc.?

3. What method of data aggregation is more appropriate in the context of its further use in the forecasting model?

On the issue of the use of the enterprises' expectations results, a study was conducted by Dovern (2006), who assesses the influence of the business expectation indicators on the forecasting model of the real GDP of Germany (in the annual measurement and up to the previous quarter) and its components. As the business expectation indicators, Dovern chose the aggregated indicators, which are published monthly by the Institute of Economic Researches IFO (Germany), in particular, the business expectation index ${ }^{1}$ (IFO business expectation index). He comes to the conclusion that the inclusion of the aggregated indicators, which reflect business expectations results, significantly improves the characteristics of the forecasting model of changes in GDP compared with the previous quarter. However, when forecasting changes in GDP in annual terms, the inclusion of the business expectation indicators does not lead to improvement of the forecasting characteristics.

Bascos-Deveza (2011), according to the results of carrying out a correlative analysis, makes the conclusion concerning the presence of a high level of correlation between the business expectation index, which is actually the average weighted value of the balance of enterprises answers, and the growth rates of Real GDP in the Philippines. However, in her study the author merely states a higher correlation value between these indicators and does not give a qualitative assessment of the forecasting models of GDP growth rate.

While studying the strengthening of forecasting characteristics of macroeconomic models, Piette and Langenus (2014), using the National Bank of Belgium - BREL ${ }^{2}$ model as an example, received the same results. The authors prove that the inclusion of business expectation indicators into the model composition improves its statistical characteristics, which is particularly important for the assessment of the GDP of the current quarter till the moment of publishing the actual statistical data.

A number of studies are devoted to the study of forecasting characteristics as separate indicators (the balance of answers) of enterprises' business expectations, and the aggregated indicators under the survey's results.

One of the first studies of this problem is the work of a research team from the National Institute of Economic Researches of Sweden (Stockholm) (Hansson, Jansson, and Löf, 2003), which is devoted to the possibility of forecasting the macroeconomic indicators of Sweden (mainly of real GDP) with the help of the business expectation indicators of the Swedish Business Tendency Survey. ${ }^{3}$ The quality of forecasting properties of the business expectation index was received by way of a comparison of the results and the characteristics of three models:

a) a basic VAR-model, in which only the macroeconomic variables (employment level, short-term and long-term interest rates, level of salary, inflation, and exchange rate) were included;

б) a VAR-model, for which the variable was the business expectation index calculated according to a dynamic factor model (DFM);

B) a VAR-model, for which the variable was one of the standard indicators of economic activities - PMI.

The authors state that the qualitative results were received from the VAR-model containing the aggregated index calculated based on a DFM. Moreover, this model allows for the possibility of receiving qualitative forecasting of real GDP not only over the short-term (up to two quarters), but also over long-term periods (up to eight quarters).

The purpose of a study by Kabundi (2004) was defining the possibility of forecasting the Real GDP of France with the help of business expectation indicators, which are collected, processed, and published by the National Bureau of Statistics of France. For building an aggregated business expectation index like in the study of Hansson, Jansson, and Löf (2003), a factor dynamic model GDFM was chosen, with the help of which were defined the principle components for the composite business expectation index (COM). The author defined the correlation level between the composite index and the variable of the Real GDP of France in annual terms as 0.86 . The forecasting characteristics of the COM business expectation index for GDP are assessed with the help of a comparison using a random walk model. The researcher concluded that the resulting indicator enables forecasting quarterly GDP for France with a rather high accuracy.

\footnotetext{
${ }^{1}$ Reflects companies' expectations in the field of production, construction, and trade for the next six months.

${ }^{2}$ BRidge equations with predictors selected on the basis of an Elastic net procedure.

${ }^{3}$ This survey is carried out by Swedish Bureau of Statistics.
} 
In their study, Greef and Nieuwenhuyze (2009) examined the benefits of an indicator of the National Bank of Belgium according to Business Surveys results, which is actually the average weighted index. The authors state that in general it is sufficient to review only the weights of separate questions as part of the aggregated index's composition. The use of other approaches, in particular the principle components method, is not reasonable because that method does not improve results and is difficult for society to understand.

Etter and Graff (2011) stress to the contrary the convenience of interpretation of the aggregated business expectation index, which is built with the help of the principle components method for the Peruvian economy. The researchers used this method for the construction of a leading composite indicator for the Peruvian economy based on business tendencies surveys, which are carried out by the National Reserve Bank of Peru. The authors are limited only by their statement of the correlative analysis results, which certifies the close relationship between the growing rates of Real GDP and the resulting indicator, which constitutes 0.85 . The forecasting assessments of GDP with the help of this indicator were not presented in the study.

Pichette and Rennison (2011) devoted a study to the issue of forecasting business activities indicators (the growth rates of Real GDP and investments) with the help of processing survey results concerning business expectations. For obtaining the aggregated index concerning enterprises' business expectations according to survey results of the Bank of Canada (Business Outlook Survey, hereinafter referred to as BOS), the authors use the principle components method and justify the use of the first principle component use (PC1) as an effective indicator of economic activities, in particular, for the assessment of enterprises' investment costs. This result is extremely important because it is usually difficult to forecast the change in the aforementioned index, and the number of indicators for its assessment is limited. This partially explains the fact that in the majority of other works (Hansson, Jansson, and Löf, 2003; Kabundi, 2004; and others), the main macroeconomic index is GDP. Additionally, Pichette and Rennison concluded that the question concerning future sales volumes and investments into equipment contain useful information for the forecasting of Real GDP dynamics and investments in the real economy sector. These indicators' inclusion into the correspondent forecasting models of GDP and its components (particularly investments) strengthens the forecasting accuracy and improves the model's statistical assessments.

The next study by Pichette (2012) was devoted to the problem of choosing the most optimal methods for building the aggregated index of enterprises' business expectations. The author compares the forecasting characteristics of the aggregated indicators, which are built with the help of tree main methods, namely: simple average, the principle components method, and factor analysis. The resulting information is assessed with the help of regressive analysis. On the basis of comparing forecasting assessments from each model, the author makes the conclusion that all three approaches give the very similar results and have almost equal forecasting assessments.

Bec and Mogliani (2013) conducted a study on the issue of forecasting the real GDP of France with the help of separate business activity indicators. One of the tasks of this study was a results comparison for the forecasting of the quarterly GDP of France on the condition that only separate components of aggregated business expectation indicators were included into the linear regressive model's composition. These components are published by the Bank of France, the National Bureau of Statistics, and the Markit Purchasing Managers Index. The study also included a comparison of the results obtained from the model, whose structure included all components of aggregated indicators of the aforementioned business expectations surveys (Fullinformation models). The results certify significantly more qualitative statistical characteristics of Full-information models, in particular, $\mathrm{R}^{\wedge} 2$ (adjusted) is equal to 0.89 , while the model in which the separate indicators were used does not exceed 0.75 . The RMSE value was also minimal for Full-information models, which gives grounds for making, among others, a conclusion about the reasonability of inclusion of indicators from survey results of different institutions (notwithstanding the number of questioned enterprises) into the composition of the forecasting model.

Piette and Langenus (2014) came to the conclusion that the study's results on the issue of business activity forecasting of Belgium do not give convincing arguments concerning the advantage of including aggregated indicators into the model's indicators. The authors state that the disaggregated data of enterprises' answers are more informative and give more qualitative assessments in comparison to the aggregated indicators.

Summarizing the literature review, we can make the following conclusions. First, the inclusion of enterprises' expectations results into a forecasting model of macroeconomic indicators (above all others is real GDP) is reasonable. Second, there is no common approach concerning the calculation methodology or components of such an index. This may be justified both by the peculiarities of the economic systems structure (for example, the importance of the services sphere for forecasting the GDP of Belgium, and hence the importance of the answers from this sector's representatives). Simultaneously, none of the researchers received convincing arguments against the concept that an aggregated index, calculated according to complex methods (such as the principle components method or the factor dynamic model), has higher qualitative forecasting characteristics than the average weighted or even separate balances of answers. 


\section{DATA, CALCULATIONS OF AGGREGATED INDICATORS, AND THEIR ANALYSIS}

The NBU carried out quarterly Business Outlook Survey since 2006. About 900 enterprises of the non-financial economic sector in 22 regions ${ }^{4}$ participate in survey, chosen so that they reflect the economic structure ${ }^{5}$ by regions and type of economic activity. The survey results are the enterprises assessments and expectations concerning the current situation and prospects for development (such as sales volumes, investments, employment), macroeconomic tendencies (in particular, inflation and exchange rate expectations), and the estimation of the links with the banking system of Ukraine (the needs for funding, credit conditions assessment, etc.). ${ }^{6}$

The main advantage of the survey is the receipt of information, which comes quicker, taking into account that the surveys are carried out in the middle of the quarter, or even absent in official statistics. This gives the grounds for using the survey results as a leading indicator, including for monetary policy decision-making. The other benefits of the survey results are their voluntariness and confidentiality. That is, we may expect that the survey results reflect a true assessment by the managers of both the situation of the enterprise and the economic environment. This gives the possibility to assess the conditions under which economic agents made decisions concerning their plans and not to make an adjustment for their possible shadow activities.

The information received under the survey results is transformed from qualitative information into quantitative data by calculating the net balance of answers. A growing balance of answers and a positive balance indicate positive changes in the economy, while a decreasing balance of answers and a negative balance indicates negative changes.

Since 2010, the NBU calculates the BEI concerning the prospects for enterprise development in the next 12 months. The results of the works of Kolesnichenko (2010) and Petryk \& Kolesnichenko (2012) certify the presence of a significant direct correlation between the BEI and the GDP in the current quarter. However, these results are contradictory because these enterprises should provide forecasts of their development for a year after the survey's date and do not reflect the current situation. But, even under such conditions, the BEI can be used as a leading indicator of the Ukrainian economy's development, at least, for one quarter in advance, because the preliminary assessment of the GDP is published by the SSSU 45 days after the end of the reported quarter, and its expended assessment after 90 days.

\section{Transformation of survey results into quantitative indicators}

The calculation of the net balance of answers on question $i$ is made using the formula:

$$
A_{i}=\frac{s_{i}^{+}-s_{i}^{-}}{s_{i}}=a_{i}^{+}-a_{i}^{-},
$$

where $A_{i}$ - is the balance of answers to question $\mathrm{i}, s_{i}^{+}-$is the amount of enterprises who answered that the index would improve/grow, $s_{i}^{-}$- is the amount of enterprises who answered that the index would worsen/decrease, $s_{i}-$ is the total amount of enterprises who answered question $\mathrm{i}$. Thus, $a_{i}^{+}-$is the share of enterprises expecting a growing index, and $a_{i}^{-}-$is the share of enterprises expecting a decreasing index (in percentage).

The BEI is calculated as the average balance of expectations to questions concerning the prospects of the enterprise development in the next 12 months under the formula:

$$
B E I=\sum_{i=1}^{5} A_{i}+100
$$

Upon calculation of the $\mathrm{BEI}$, the balances of answers for the following questions are used:

1) How would you assess the financial and economic conditions of your enterprise in the next 12 months?

2) How will the total volume of products (services) sales of your enterprise change in the next 12 months?

3) How will the investments for building change at your enterprise in the next 12 months?

4) How will the investments for machinery, equipment and instruments change at your enterprise in the next 12 months?

5) How will the number of employees change at your enterprise in the next 12 months?

\footnotetext{
${ }^{4}$ Except the Autonomous Republic of Crimea, Donetsk and Luhansk regions.

${ }^{5}$ The NBU uses quota sampling, which is formed proportionally to the region's contribution and the concrete activity type in the production of the gross added value of Ukraine.

${ }^{6}$ The survey methodology is explained in detail in the "Methodological Principles of Surveys Concerning the Business Outlook by the National Bank of Ukraine" at: http:// www.bank.gov.ua/doccatalog/document?id=76819
} 
For composition the aggregated index using the principle components method based on the survey's results, the extended questions list (Table 1) was used in comparison with those use for calculating the BEl. According to the theoretical assumptions, all of these questions are characterized by a correlation with the economic activities in the country. All data are the quarterly results of the enterprises' surveys for the period from the 2nd quarter of 2006 till the 3rd quarter of 2015.

\section{Table 1. Questions used for calculating the index under the principle components method}

\begin{tabular}{|l|l|}
\hline No. & \\
\hline $\mathbf{A 1}$ & How would you assess the current financial and economic condition of your enterprise? \\
\hline $\mathbf{A 2}$ & How would you assess the financial and economic condition of your enterprise in the next 12 months? \\
\hline $\mathbf{A 3}$ & How will the total volumes of products (services) sales of your enterprise change in the next 12 months? \\
\hline $\mathbf{A 4}$ & How will the total volumes of products (services) sales of your enterprise change at the external market in the next 12 \\
\hline $\mathbf{A 5}$ & months? \\
\hline $\mathbf{A 6}$ & What is the current level of inventory of finished goods in comparison with the desired level? \\
\hline $\mathbf{A 7}$ & How will the investment for buildings change at your enterprise in the next 12 months? \\
\hline $\mathbf{A 8}$ & How will the investments for machinery and equipment change at your enterprise in the next 12 months? \\
\hline $\mathbf{A 9}$ & How will the number of employees change at your enterprise in the next 12 months? \\
\hline $\mathbf{A 1 0}$ & How will unit costs at your enterprise change in the next 12 months? \\
\hline $\mathbf{A 1 1}$ & How will the need for borrowed money to finance your activities change in the next 12 months? \\
\hline $\mathbf{A 1 2}$ & How have the conditions for receiving financing from banks for your enterprise changed over the last three months? \\
\hline $\mathbf{A 1 3}$ & What are the enterprise's plans with regard to obtaining loans? \\
\hline
\end{tabular}

The idea of the principle components method consists of reducing the dimensions of the input data matrix while providing maximum retention of information. The description of the calculation algorithm of the principle components is set out, in particular, at Stock and Watson (2002) and Pichette (2012). In general, the principle components $\mathrm{a}_{\mathrm{j}}[\mathrm{j}=1 \ldots \mathrm{k}]$ are the linear combination of the input variables $x j(j=1, \ldots, n)$. One of this method's peculiarities is the impairment of useful information with the components order, that is, it is actually reasonable to examine only the first several components (as a rule - not more than the first four).

In our case, the first three components describe about $84 \%$ of the actual value dynamics (Figure 1), which makes it reasonable to focus only on their analysis according to Kaiser's Rule.

\section{Figure 1. Contributions of principle components}

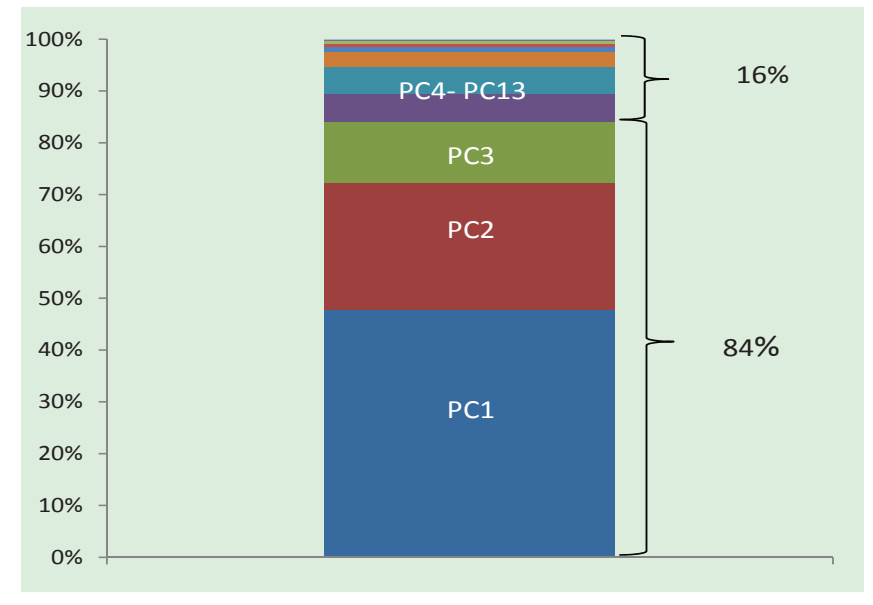

Source: NBU staff estimates under the surveys results. 
The influence of each of the questions A1-A13 on the dynamics of principle components is using correspondent coefficients or weights (Table 2, Figure 2). Because each of the principle components is orthogonal (that is, perpendicular) to one another, the coefficients in each principle component change accordingly. An analysis of each component structure and the coefficients comprising a part of each of the three principle components shows the following.

Table 2. Coefficients values in the principle components structure

\begin{tabular}{|c|c|c|c|}
\hline Indicators & pc1 & pc2 & $p$ c3 \\
\hline A7 & 0.378284 & 0.15514 & 0.029207 \\
\hline A8 & 0.374323 & 0.13509 & 0.041912 \\
\hline A9 & 0.373807 & 0.166187 & 0.049064 \\
\hline A2 & 0.346234 & 0.087475 & 0.116725 \\
\hline A3 & 0.345504 & -0.25284 & 0.051414 \\
\hline A4 & 0.326348 & -0.28299 & 0.052355 \\
\hline A1 & 0.300891 & 0.24508 & 0.119373 \\
\hline A13 & 0.236324 & -0.3864 & 0.056431 \\
\hline A11 & 0.22871 & -0.10799 & -0.37935 \\
\hline A12 & 0.084745 & 0.506187 & -0.05053 \\
\hline A10 & 0.000756 & -0.00492 & -0.73463 \\
\hline A6 & -0.10368 & 0.494853 & 0.179853 \\
\hline A5 & -0.12113 & -0.23716 & 0.489953 \\
\hline
\end{tabular}

Figure 2. Weights (coefficients) of questions A1-A13 in the composition of the first three principle components

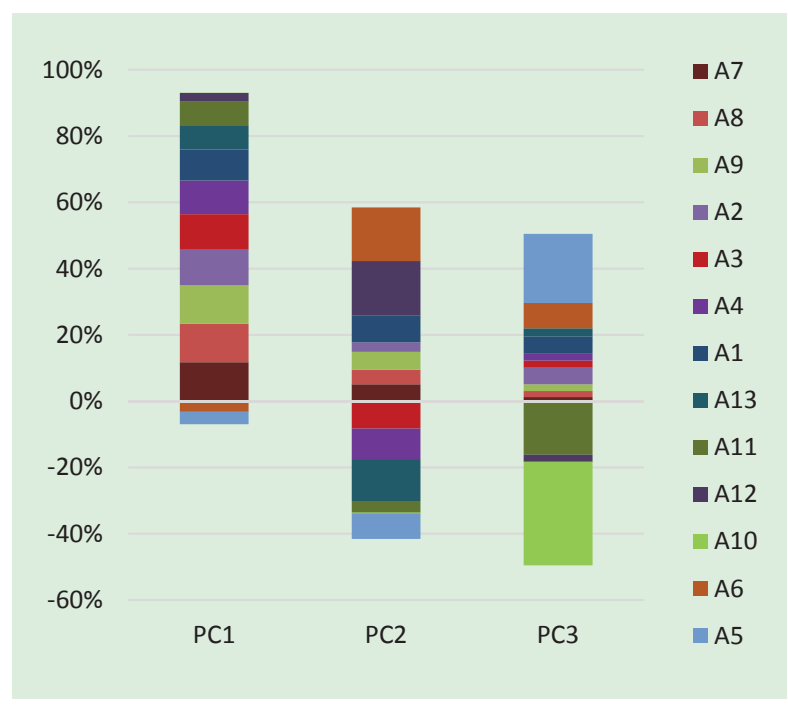

Source: NBU staff estimates under the survey results. 
The first principle component (PC1) correlates with the majority of variables, which can be used for the assessment and forecasting of economic activities, in particular:

-all forecasting estimates of enterprises' management for one year:

- The change of the investments for building and equipment (A7 and A8);

- The change of the number of employees (A9);

- The change of the financial and economic conditions of the enterprise (A2);

- The change of the total volumes sales (A3);

- The change of the volumes sales in the external market (A4).

- The assessment of the current financial and economic conditions of the enterprise (A1).

From an economic point of view, such a structure of the first principle component is fully acceptable, because usually investments increase, employment rises, and sales volumes increases lead to a growth in economic activities (in particular, the GDP), and the current development of enterprises influences the assessment of future prospects.

Simultaneously, the influence of the change in crediting conditions is quite insignificant, which is explained both by the complexity of enterprises' access to credit resources for the last 7 years, and their high value. The negative influence on economic activities in the PC1 structure has the increase of idle capacity at the enterprise (A6) and the increase of volumes of inventories (A5), which is also considered as justified.

Taking into account the previously mentioned, the first principle component can be used as a leading indicator of economic activities.

\section{Figure 3. PC1 and Real GDP Growth (y-0-y), \%}

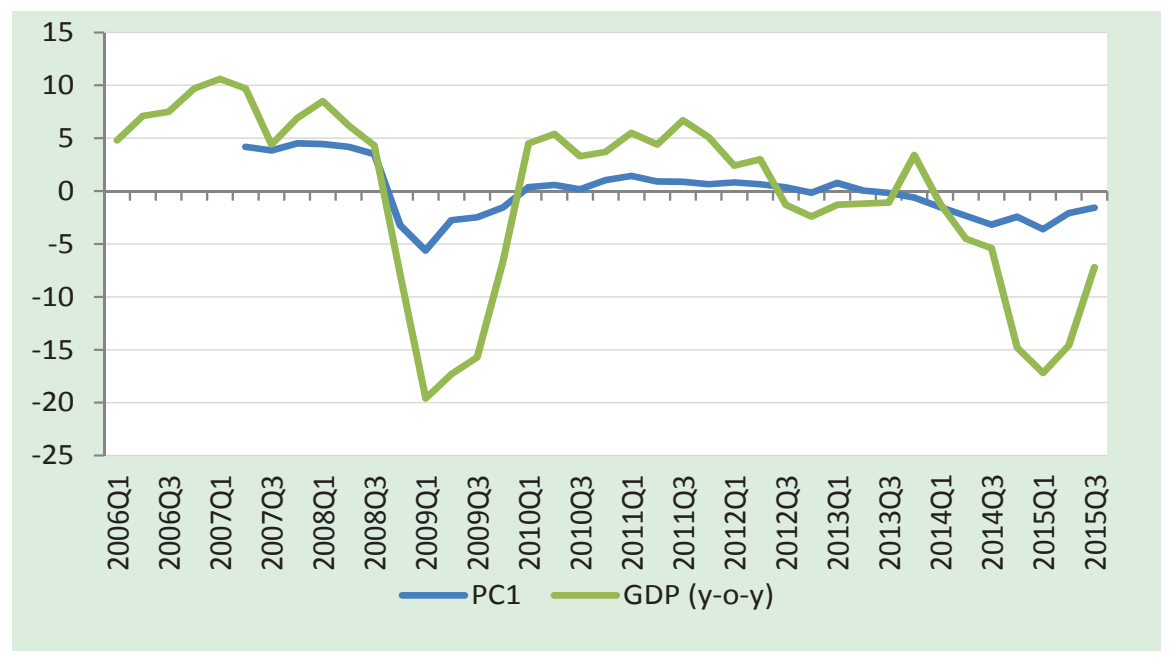

Source: NBU staff estimates under the survey results.

The structure of the second principle component (PC2) corresponds more to the task of assessing the influence of the financial conditions on economic activity. Thus, the key factors influencing this component's value are the complexity of enterprises' access to financing from banks (A12), that is, the rigidity of credit conditions, as well as the increase in idle capacity (A6).

The analysis of the PC2 dynamics (Figure 4), certifies that since the 3rd quarter of 2010 the crediting conditions almost do not influence GDP dynamics and business activities in Ukraine. Actually, started from this period, extremely unfavorable conditions for loans were formed, which have not changed up to today. Under such conditions, enterprises are not interested in borrowing to support and/or to stimulate the development of their own activities. Also of interest is the analysis of the balance of credit conditions and enterprises' plans concerning obtaining loans during 2007-2009. After intensification of the financial and economic crisis in 2008, enterprises suffered from significant problems related to the availability of credit resources, which were balanced by lower demand for these resources. So the PC2 value approximated to zero, because enterprises' plans concerning borrowing (A13) and the changes in expectations of products sales volumes ( $\mathrm{A} 3$ and $\mathrm{A} 4$ ) were leveled by the complexity of access to banking resources (A12) and the capability to satisfy unexpected demand (A6). 
Figure 4. PC2 and Real GDP Growth (y-o-y), \%

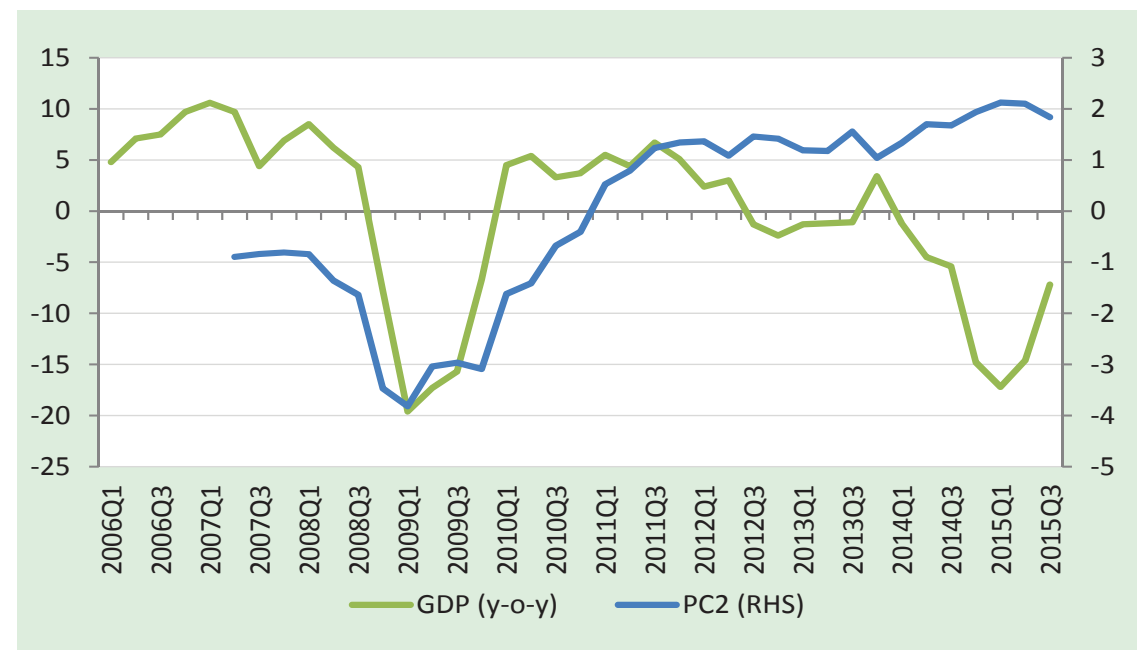

Source: NBU staff estimates under the survey results.

The key factors influencing the third principle component value (PC3) are the change of the unit costs at enterprises in the next 12 months (A10) and the level of inventories (A5). The change of unit costs was included into the index composition with a negative sign (Table 2 ), because growing costs may negatively influence business activity.

The analysis of the third principle component dynamics (PC3) and GDP (Figure 5) certifies that, before the 1st quarter of 2014, enterprises' expectations concerning the increase of unit costs were neutral to economic activity. Generally, this is typical for small commodity-oriented economies, where prices and demand for products are formed in external markets. The sharp devaluation of the hryvnia exchange rate and the subsequent increase of a unit cost, combined with the simultaneous fall of world prices and demand for Ukrainian export products, formed the corresponding enterprises' expectations (the negative significant influence of unit cost, which was not compensated by other factors), which for the first time in the history of observations coincided with the GDP dynamics in the country.

Figure 5. PC3 and Real GDP Growth (y-o-y), \%

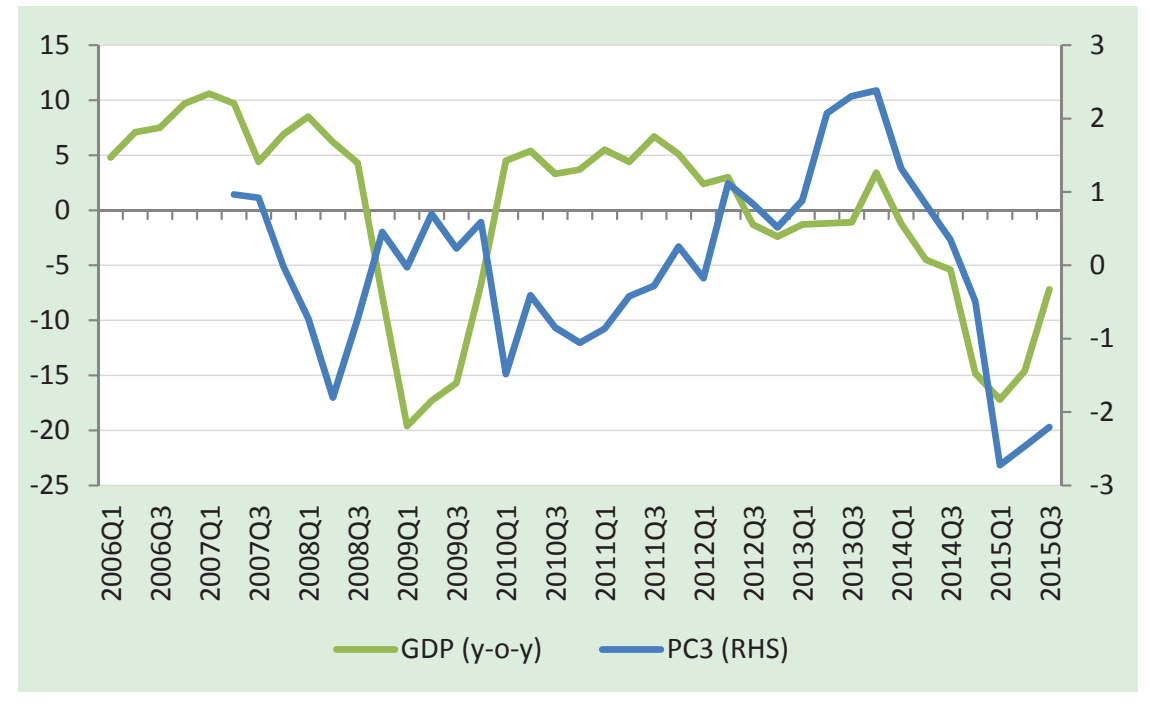

Source: NBU staff estimates under the survey results. 
The greatest deviations between GDP dynamics and first three principle components are observed during the periods of the greatest crisis aggravation in Ukraine, that is, in the 4th quarter of 2008, the 1st quarter of 2009, and the 1st-2nd quarters of 2015. Typical for all periods is the overestimation of crisis influence by enterprises, which within stable periods provided enterprises expectations better than macroeconomic indicators (except 2013, when the expectations worsened quicker than the level of business activities decreased).

\section{USE OF THE AGGREGATED INDICATORS TO FORECAST GDP}

To assess the forecasting power of the constructed PC1 indicator and its comparison with the BEI forecasting power, a correlation analysis of these indicators and real GDP was carried out (Table 3). The closest relationship was found between the change of GDP and the BEI and PC1 in the current quarter. Therefore, the relationship between GDP and the BEI is somewhat better in comparison with the connection between the GDP and PC1. In addition, a closer correlation is observed between the $\mathrm{BEI}, \mathrm{PC1}$, and the change of GDP y-o-y (to the corresponding quarter of the previous year), which is connected with the 12-month horizon of questions, thus, the seasonality has already been excluded from the survey results.

\section{Table 3. Correlation Between BEI, PC1, and Real GDP Growth}

\begin{tabular}{|c|c|c|c|c|}
\hline Lag & \multicolumn{2}{|c|}{ GDP (q-o-q, SA) } & \multicolumn{2}{c|}{ GDP $(\mathbf{y}-\mathbf{0}-\mathbf{y})$} \\
\hline & BEI & PC1 & BEI & PC1 \\
\hline $\mathbf{- 4}$ & 0.1346 & -0.0220 & 0.1020 & -0.0444 \\
\hline $\mathbf{- 3}$ & 0.4587 & 0.3483 & 0.2702 & 0.1543 \\
\hline $\mathbf{- 2}$ & 0.6525 & 0.5588 & 0.4789 & 0.3857 \\
\hline $\mathbf{- 1}$ & 0.7350 & 0.6470 & 0.7289 & 0.6524 \\
\hline $\mathbf{0}$ & 0.7103 & 0.6201 & 0.9105 & 0.8580 \\
\hline $\mathbf{1}$ & 0.3248 & 0.2114 & 0.8344 & 0.7461 \\
\hline $\mathbf{2}$ & 0.0024 & -0.0841 & 0.5918 & 0.4881 \\
\hline $\mathbf{3}$ & -0.1130 & -0.2552 & 0.3099 & 0.1772 \\
\hline $\mathbf{4}$ & -0.1847 & -0.3628 & 0.0023 & -0.1726 \\
\hline
\end{tabular}

Figure 6. BEI, PC1, and Real GDP Growth (y-o-y), \%

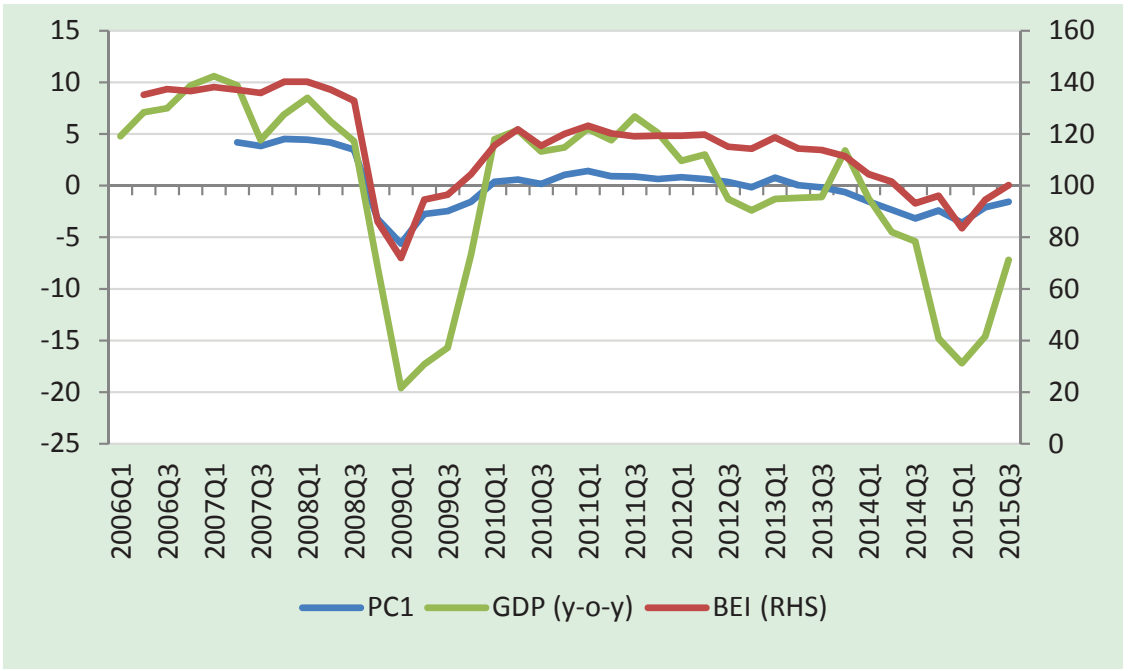

Source: NBU staff estimates under the survey results. 
Figure 7. BEI, PC1, and Real GDP Growth (q-o-q, SA), \%

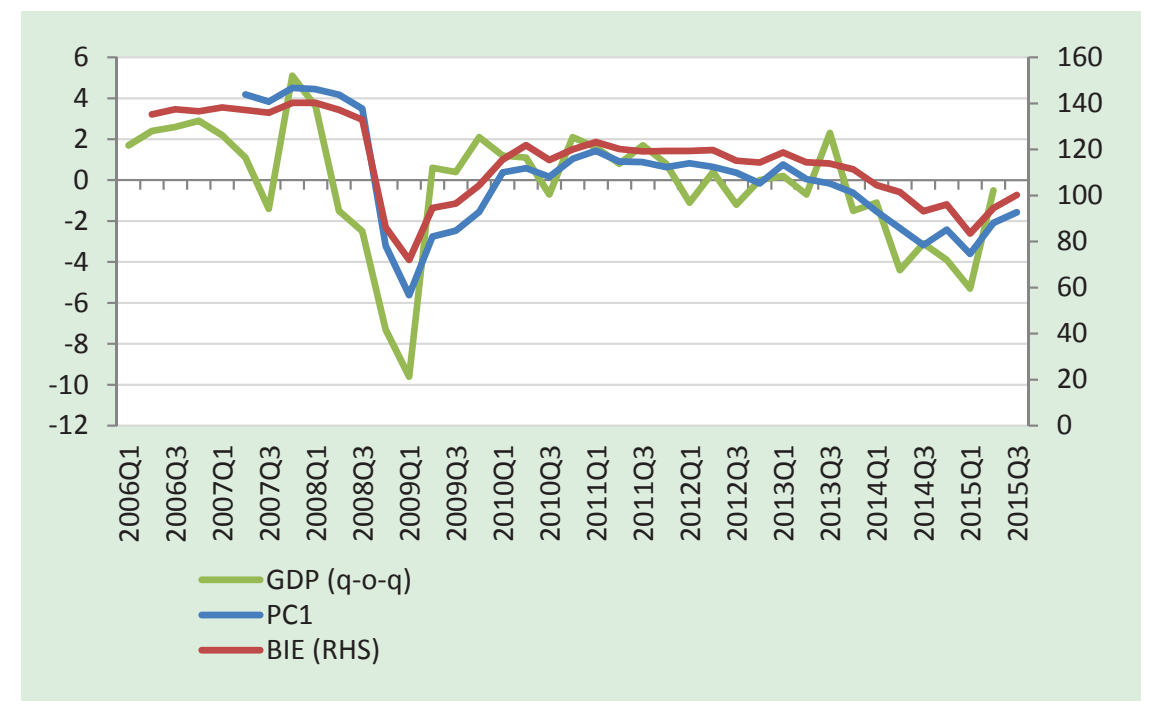

Source: NBU staff estimates under the survey results.

The tight relationship between the indicators of GDP, the BEI and PC1 gives the possibility of their use for nowcasting of economic development. For this purpose, we have built linear regression equations for a different set of indicators:

- On the basis of GDP (baseline for a forecast quality assessment) ${ }^{7}$ :

$G D P_{t}=c_{1}+\alpha_{1} \times G D P_{t-1}+\varepsilon_{t 1}(1)$,

- On the basis of PC1:

$G D P_{t}=c_{2}+\alpha_{2} \times G D P_{t-1}+b_{2} \times P C 1_{t}+\varepsilon_{t 2}(2)$,

- On the basis of the balance of answers concerning total sales volumes (BA):

$G D P_{t}=c_{3}+\alpha_{3} \times G D P_{t-1}+b_{3} \times B A_{t}+\varepsilon_{t 3}(3)$,

- On the basis of the BEI:

$G D P_{t}=c_{4}+\alpha_{4} \times G D P_{t-1}+b_{4} \times I D O_{t}+\varepsilon_{t 4}(4)$.

The next step was building the corresponding equations for GDP components - the final consumption expenditure (hereinafter referred to as consumption) and the gross fixed capital formation (hereinafter referred to as investments) under the same principle. As the balance of answers for the equation (3) concerning consumption uses the balance of answers related to total sales volumes, and for investments - the balance of answers concerning investments for building. The equations were built separately for the different values of GDP and its components: the changes compared with the corresponding quarter of the previous year (hereinafter $y-0-y$ ) and compare with the previous quarter, seasonally adjusted (hereinafter - q-o-q). In building PC1, the equations were assessed for the period from the 2nd quarter of 2006 to the 3rd quarter of 2015.

The statistical characteristics for the basic equation (1) for GDP, investments, and consumption both q-o-q and y-o-y (Table 4) indicate a sufficiently weak capability of the AR(1) model. This means that the forecasting model strength must be increased by the inclusion of additional variables, in particular, indicators that characterize the business expectations.

${ }^{7}$ Represents the autoregressive equation $A R(1)$. 
Table 4. Statistical properties of the equations ${ }^{8}$

\begin{tabular}{|c|c|c|c|c|c|c|}
\hline & $\begin{array}{l}G D P_{t} \\
q / q\end{array}$ & $\begin{array}{l}G D P_{t} \\
y / y\end{array}$ & $\begin{array}{l}\ln v_{t} \\
q / q\end{array}$ & $\begin{array}{l}\ln v_{t} \\
y / y\end{array}$ & $\begin{array}{c}\text { Cons }_{t} \\
q / q\end{array}$ & $\begin{array}{c}\text { Cons }_{t} \\
y / y\end{array}$ \\
\hline C & $\begin{array}{c}-0.14 \\
{[-0.34]}\end{array}$ & $\begin{array}{c}-0.34 \\
{[-0.45]}\end{array}$ & $\begin{array}{c}-1.17 \\
{[-0.71]}\end{array}$ & $\begin{array}{c}-1.17 \\
{[-0.62]}\end{array}$ & $\begin{array}{c}0.36 \\
{[0.65]}\end{array}$ & $\begin{array}{c}-0.36 \\
{[-0.39]}\end{array}$ \\
\hline$G D P_{t-1} q / q$ & $\begin{array}{l}-0.53 \\
{[3.78]}\end{array}$ & & & & & \\
\hline$G D P_{t-1} y / y$ & & $\begin{array}{c}0.85 \\
{[9.65]}\end{array}$ & & & & \\
\hline $\ln v_{t-1} q / q$ & & & $\begin{array}{c}0.34 \\
{[2.14]}\end{array}$ & & & \\
\hline $\ln v_{t-1} y / y$ & & & & $\begin{array}{c}0.85 \\
{[10.25]}\end{array}$ & & \\
\hline Cons $_{t-1} q / q$ & & & & & $\begin{array}{c}0.39 \\
{[2.32]}\end{array}$ & \\
\hline Cons $_{t-1} y / y$ & & & & & & $\begin{array}{c}0.89 \\
{[10.56]}\end{array}$ \\
\hline$R^{2}$ (adjusted) & 0.28 & 0.89 & 0.12 & 0.75 & 0.14 & 0.76 \\
\hline RMSE-ratio & 2.87 & 3.41 & 10.07 & 20.51 & 3.41 & 9.72 \\
\hline
\end{tabular}

The inclusion of the business survey indicators - the first principle component (PC1) (equation 2), the separate balances of answers (BA) (equation 3), and the BEI (equation 4) improved the assessments and the statistical properties of the basic model both for GDP and its components investments and consumption significantly (Table 5). This concerns quarterly and annual measurements of the forecasting indicators.

The best results were received from equations that included the BEI (except investments), which is unexpected because the BEI is the just simple average of the balances of answers. Thus, such a conclusion corresponds to the results of Greef and Nieuwenhuyze (2009), who insisted on the inadvisable use of the principle components method, as well as Pichette (2012), who did not receive convincing arguments as to the benefit of this method.

For investments, the qualitative properties are shown by the equation that included the balance of expectations concerning investments in building. Such a result corresponds to the conclusions of Pichette (2012) and Piette and Langenus (2014) in the context of the more self-descriptiveness and forecasting power of the separate balances of answers, but not the aggregated indicators.

The results also confirmed the availability of a statically significant correlation between the enterprises' expectations and the business activity in the reporting quarter $t$, that is, the expectations are adaptive and depend on the current situation and the past development, and do not reflect the forecast over the next year. This result is consistent with the results of other studies, in particular, Kabundi (2004), Piette and Langenus (2012), Pichette (2012), and others.

The statistical assessments and the properties both of the equations and the separate indicators in whole are adequate and correspond to the results received by other researchers. Simultaneously, a value of statistical properties of the equations are worse than by other researchers (in particular, in the work of Pichette (2012) for the GDP of Canada). However, taking into account the significant structural changes in the Ukrainian economy and the shock drop of GDP through the crises in 2008-2009 and 2014-2015, this is a sufficiently acceptable result. 
Table 5. Statistical properties of the extended equations ${ }^{9}$
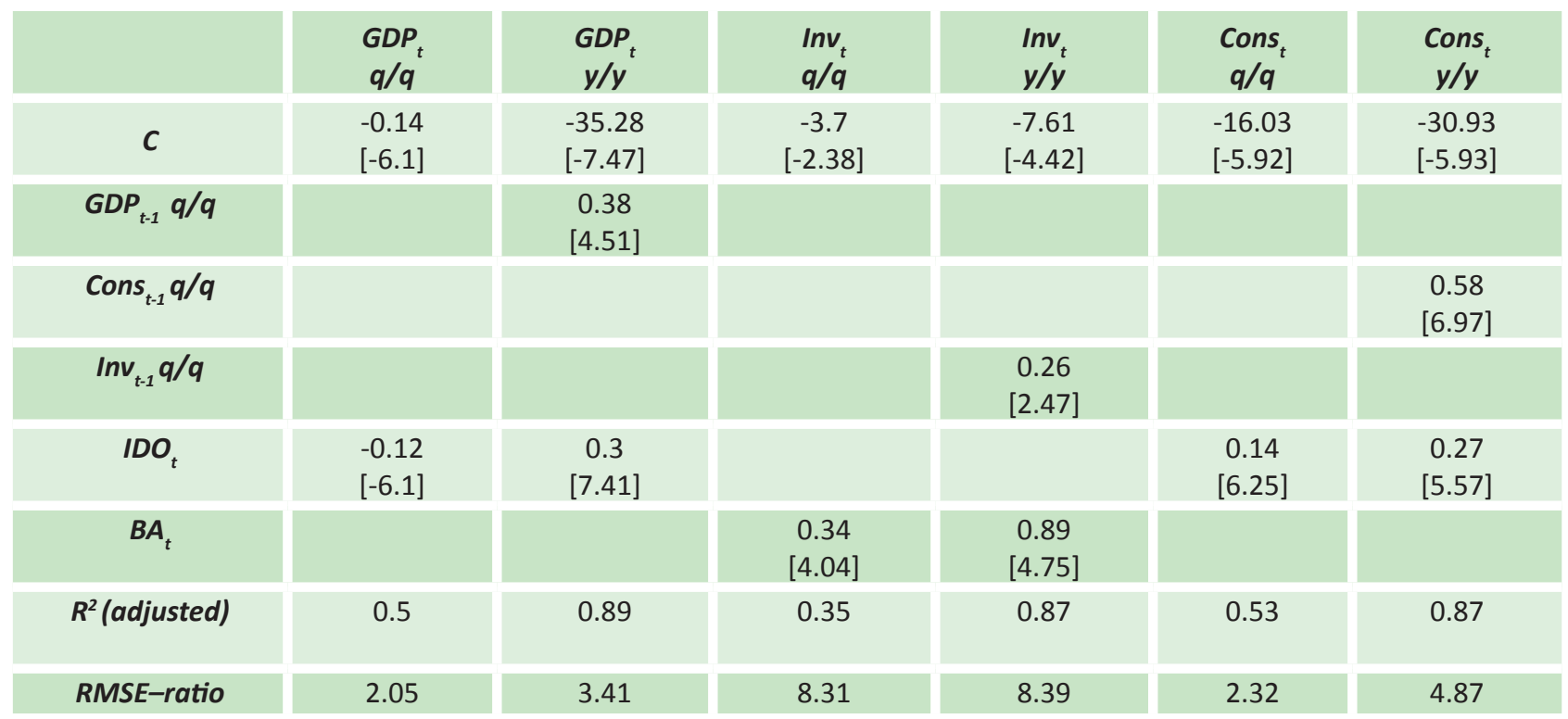

The results certify that the BEI calculation approach, which were accepted in the NBU, provide better forecast of the GDP dynamics and consumption as the GDP component than the index built under the principle components approach. Thus, the BEl can be used for nowcasting of GDP and its components with help of the developed equations. Thus, the sufficiently high RMSE values are probably the consequences of the high volatility of GDP, consumption, and investments within the period, which is the basis for the calculations.

\section{CONCLUSIONS}

The study conducted had the purpose of checking the possibility of using Business Outlook Survey results, which are carried out by the NBU since 2006, for nowcasting of Ukrainian GDP and its components (investments and consumption). The study's results provide the possibility to make the following conclusions.

First, the survey results have strong power for forecasting Ukrainian business activity. The statistical properties of the equations, which included aggregated business expectation indicators or the separate balance of answers, were much better than the results of the basic model. On the other hand, the results certify that enterprises' forecasting assessments rather reflect their current situation and not the development over the next 12 months. Thus, enterprises' expectations in Ukraine are adaptive, that is, depend on the current situation and the past development. This conclusion was expected as almost the same results were received in the most of studies concerning the use of survey results in the forecasting of economic development.

Second, the business expectation index BEI, which is calculated by the NBU, is the actual simple average of the balances of answers to questions concerning the prospects of enterprises' activities over the next 12 months, provides for changes of GDP and consumption as the GDP component with more reliability than the index calculated under the principle components method (the first principle component). Thus, the BEI can be fully used for nowcasting of GDP using the developed equation. This result is unexpected, because an increase of the index components list theoretically allows for the possibility to more accurately take into account the influence of the smallest changes in different indicators on change in GDP. Thus, this does not contradict the results of Pichette (2012) studies and agrees with the conclusions both of Greef and Nieuwenhuyze (2009) concerning the inadvisable use of the principle components method, and Piette and Langenus (2014) in the context of the more convenient use of separate balances of answers for building models than the aggregated indicators.

Third, using the principle components method proved to be useful only for the assessment of the extended factors list, which nevertheless influenced the dynamics of business activities. In particular, the first principle component is based on the current assessment and the forecast; the second one is more connected with the complexity of access to financing from banks, which gives the possibility to assess the influence of financial conditions on economic activities. The key factors influencing the value of the third principle component are the unit costs and the level of inventories, which gives the possibility to assess the influence of demand and the producers prices fluctuation on the economic development.

\footnotetext{
${ }^{9}$ The values in the Table - calculated coefficients; value in brackets [] - t-statistics.
} 


\section{References}

- Banerjee A., Marcellino M., Masten I. (2003). Leading Indicators for Euro-area Inflation and GDP Growth. Working Paper, No. 235.

- Bascos-Deveza T. (2011). Quantifying qualitative data from expectation surveys: how well do expectation surveys forecast inflation? IFC Bulletin, No. 34, Bank for International Settlements, pp. 128-137.

- Burkart O., Coudert V. (2000). Leading Indicators of Currency Crises in Emerging Economies, Banque de France.

- Cesaroni T. (2010). Estimating potential output using business survey data in a SVAR framework. Economics Bulletin, Vol. 30, No. 3, pp. 2249-2258.

- Chamberlin G. (2007). Forecasting GDP using external data sources. Economic \& Labour Market Review, Vol. 1, No. 8, Office for National Statistics, pp. 18-23.

- Cheung C. (2009). Are Commodity Prices Useful Leading Indicators of Inflation? Discussion paper / Document d'analyse, No. 2009-5, Bank of Canada.

- Etter R., Graff M. (2011). A composite leading indicator for the Peruvian economy based on the BCRP's monthly business tendency surveys. Working Paper series, No. 2011-006 (Serie de Documentos de Trabajo), Banco Central de Reserva del Peru.

- Greaf I., Nieuwenhuyze C. (2009). The National Bank of Belgium's new business survey indicator, National Bank of Belgium.

- Hansson J., Jansson P., Löf M. (2003). Business Survey Data: Do They Help in Forecasting the Macro Economy? Working Paper, No. 84, The National Institute of Economic Research.

- Klein L., Ozmucur S. (2004). Some Possibilities for Indicator Analysis in Economic Forecasting. Oxford University Press, pp. 243-257.

- Kolesnichenko N. (2010). Composition of a synthetic index by results of business expectations surveys conducted by the National Bank of Ukraine. Visnyk of the National Bank of Ukraine, No. 6, pp. 6-9.

- Martin M. (2004). The Bank of Canada's Business Outlook Survey. Bank of Canada Review, pp. 3-8.

- Martin M., Papile C. (2004). The Bank of Canada's Business Outlook Survey: An Assessment, Bank of Canada Review, Working Paper, No. 2004-15 / Document de travail, No. 2004-15.

- Moon H., Lee J. (2013). Forecast evaluation of economic sentiment indicator for the Korean economy, IFC Bulletin, No. 36, Bank for International Settlements, pp. 180-190.

- Petryk O., Kolesnichenko N. (2012). Business surveys as a forecasting and communication mechanism of a central bank. Visnyk of the National Bank of Ukraine, No. 11, pp. 3-11.

- Pichette L. (2012). Extracting Information from the Business Outlook Survey Using Statistical Approaches. Discussion paper / Document d'analyse, No. 2012-8, Bank of Canada.

- Pichette L., Rennison L. (2011). Extracting Information from the Business Outlook Survey: A Principal-Component Approach, Bank of Canada Review, Autumn 2011, pp. 21-28.

- Stock J.H., Watson M.W. (1989). New Indexes of Coincident and Leading Economic Indicators, NBER Macroeconomics Annual, Vol. 4, pp. 351-394.

- Stock J.H., Watson M.W. (2002). Forecasting Using Principal Components From a Large Number of Predictors, Journal of the American Statistical Association, Vol. 97, No. 460, pp. 1167-1179.

- Stock J., Watson M. (2002). Macroeconomic Forecasting Using Diffusion Indexes. Journal of Business and Economic Statistics, No. 20, pp. 147-162. https://doi.org/10.1198/073500102317351921 